\title{
EFEKTIVITAS PENYULUHAN DENGAN MEDIA POSTER TERHADAP PENGETAHUAN DAN SIKAP ISTRI PADA KEKERASAN DALAM RUMAH TANGGA
}

\author{
Yulia Herawati ${ }^{1)}$, Nur Aini ${ }^{2}$ \\ ${ }^{1)}$ Program Sarjana Terapan Kebidanan, STIKes Mitra RIA Husada \\ ${ }^{2)}$ Program Studi S1 Kesehatan Masyarakat \\ herawati.yulia1007@gmail.com
}

\begin{abstract}
ABSTRAK
Pada tahun 2014 terdapat 293.220 kasus, tahun 2015 meningkat menjadi 321.750 kasus, dan tahun 2016 terdapat terdapat 245.548 kasus. Kekerasan terhadap istri menempati peringkat pertama. Pada tahun 2014 terdapat 5.102 kasus, tahun 2015 meningkat 9\% yaitu menjadi 5.561 kasus, dan tahun 2016 terdapat 5.784 kasus. Penelitian ini menggunakan jenis penelitian eksperimen semu (quasi experiment) dengan rancangan one-group pr-etest dan post-test yaitu untuk melihat efektivitas penyuluhan dengan media poster terhadap pengetahuan dan sikap istri pada KDRT di Jalan Masjid Baru RT 12 RW 01 Jakarta Selatan. Jumlah responden dalam penelitian ini adalah 60. Pengambilan sempel menggunakan sempel jenuh yaitu seluruh istri. Instrumen penelitian ini adalah kuisioner. Hasil penelitian menunjukkan adanya efektivitas penyuluhan dengan media poster terhadap pengetahuan dengan $P$-value 0,002 dan adanya efektivitas penyuluhan dengan media poster terhadap sikap istri dengan $P$-value 0,009 . Kesimpulan menunjukkan adanya efektivitas penyuluhan dengan media poster terhadap pengetahuan dan sikap istri pada KDRT. Diharapkan pengetahuan dan sikap istri menjadi lebih baik pada KDRT agar korban dalam kasus KDRT tidak semakin bertambah.
\end{abstract}

Kata Kunci: Kekerasan dalam rumah tangga

\section{PENDAHULUAN}

Kekerasan Dalam Rumah Tangga (KDRT), yang sering kali disebut juga sebagai kekerasan domestik adalah pola tingkah laku koersif untuk mengatur orang lain ${ }^{1}$. Menurut Undang-Undang nomor 23 tahun 2004 tentang Penghapusan KDRT, bentuk-bentuk KDRT (Pasal 5) yaitu kekerasan fisik, kekerasan psikis, kekerasan seksual, dan penelantaran rumah tangga. Ironisnya jumlah kekerasan yang terjadi semakin hari semakin meningkat baik secara kuantitatif maupun kualitatif. ${ }^{2}$. KDRT dapat memberi dampak buruk secara kesehatan fisik dan psikologi. Oleh karena itu, seorang istri seharusnya memiliki pengetahuan yang baik tentang KDRT. Pengetahuan istri terhadap KDRT masih kurang. Kurangnya pengetahuan istri terhadap KDRT membuat kekerasan menjadi sesuatu hal yang biasa. Berdasarkan penelitian yang dilakukan Sari (2008) di Kabupaten Langkat menunjukkan bahwa terdapat 55,9\% istri mempunyai pengetahuan KDRT yang masih rendah. ${ }^{3}$ Penelitian selanjutnya dilakukan oleh Fransiska (2012) di Depok terdapat 64,5\% istri mempunyai pengetahuan KDRT yang masih rendah. ${ }^{1}$ World Health Organization (WHO) menyatakan bahwa satu dari empat wanita di seluruh dunia adalah KDRT, dengan orang-orang di Asia dan Timur Tengah yang paling besar jumlahnya. Wilayah Asia dan Timur Tengah dinaungi dengan beberapa negara, seperti salah satunya Indonesia, namun Indonesia bukan merupakan salah satu negara yang berada di wilayah Asia, dengan skala kekerasan perempuan terbesar ${ }^{4}$. Catatan Tahunan (CATAHU) Komisi Nasional Perempuan Indonesia memuat informasi dari data yang terkumpul, jenis kekerasan yang menonjol adalah kasus KDRT. ${ }^{5}$ Berdasarkan data tersebut pada tahun 2014 terdapat 293.220 kasus, tahun 2015 meningkat menjadi 321.750 kasus, dan tahun 2016 terdapat 245.548 kasus. Kekerasan terhadap istri menempati peringkat pertama. Pada tahun 2014 terdapat 5.102 kasus, tahun 2015 meningkat 9\% yaitu menjadi 5.561 kasus, dan tahun 2016 terdapat 5.784 kasus. Menurut laporan Catatan 
Tahunan (Catahu), Lembaga Bantuan Hukum (LBH) Jakarta, dan Asosiasi Perempuan Indonesia untuk Keadilan (APIK) Jakarta menyebutkan kasus KDRT di Jakarta cukup tinggi yaitu pada tahun 2014 terdapat 527 kasus, tahun 2015 terdapat 396 kasus, dan terjadi peningkatan pada tahun 2016 menjadi 2.552 kasus. Faktorfaktor yang menyebabkan kurangnya pengetahuan dan sikap istri terhadap KDRT adalah usia, pendidikan, dan pekerjaan. Usia mempengaruhi daya tangkap dan pola pikir seseorang. Semakin bertambah usia akan semakin berkembang pula daya tangkap dan pola pikirnya, sehingga pengetahuan yang diperoleh semakin banyak. Selanjutnya adalah pendidikan yang merupakan proses pembelajaran untuk meningkatkan kemampuan tertentu. Semakin tinggi tingkat pendidikan, semakin mudah untuk dapat menyerap pengetahuan dan lebih memahami bagaimana dalam menyikapi suatu masalah. Lalu pada istri yang mempunyai pekerjaan akan mempunyai kegiatan sehari-hari dan memiliki waktu yang lebih untuk memperoleh informasi. KDRT dapat memberi dampak buruk secara fisik dan psikologi. Dampak pada fisik tidak hanya menimbulkan luka, tetapi juga dapat menimbulkan efek lain dari luka tersebut. Misalnya nyeri kronis dan gangguan imun juga dapat terjadi sehingga korban rentan terhadap penyakit. Sedangkan dampak psikologis yang terjadi yaitu korban dapat merasakan trauma psikologis, adanya rasa ketakutan, hilangnya rasa percaya diri, hilangnya kemampuan untuk bertindak, rasa tidak berdaya, dan merasa rendah diri. ${ }^{9}$

\section{METODE}

Penelitian ini menggunakan jenis penelitian kuantitatif dengan rancangan deskriptif analitik dan pengambilan data dengan data primer. Adapun Kriteria sampel meliputi :

Kriteria Inklusinya yaitu :

a. Istri di Jalan Masjid Baru RT 12 RW 01 Kecamatan Pasar Minggu, Jakarta Selatan.

b. Istri yang bersedia menjadi responden.

c. Lingkungan yang sering terjadi adanya kasus KDRT.

Kriteria Eksklusinya yaitu:

a. Istri yang tidak hadir saat penelitian.

Teknik sampling yang digunakan pada penelitian ini yaitu sampel jenuh atau total sampling. Analisis Univariat menggunakan presentase dari Efektivitas Penyuluhan dengan Media Poster terhadap Pengetahuan dan Sikap Istri Sebelum dan Sesudah diberikan Penyuluhan. Analisis Bivariat menggunakan menggunakan Uji Mc Nemar untuk mengetahui Penyuluhan dengan Media Poster terhadap Pengetahuan dan Sikap Istri Sebelum dan Sesudah diberikan Penyuluhan. 


\section{HASIL DAN PEMBAHASAN}

Tabel 1

Distribusi Frekuensi Pengetahuan dan Sikap seluruh Istri Sebelum dan Sesudah Diberikan Penyuluhan tentang KDRT di Jalan Masjid Baru RT 12 RW 01, Jakarta Selatan

\begin{tabular}{|c|c|c|c|c|c|c|c|}
\hline \multirow{2}{*}{\multicolumn{2}{|c|}{ Variabel }} & \multicolumn{3}{|c|}{ Pre - Test } & \multicolumn{3}{|c|}{ Post - Test } \\
\hline & & Mean & $\mathbf{n}$ & $\%$ & Mean & $\mathbf{n}$ & $\%$ \\
\hline \multicolumn{8}{|c|}{ Pengetahuan } \\
\hline - & Kurang & & 38 & 63,3 & & 25 & 41,6 \\
\hline • & Baik & & 22 & 36,7 & & 35 & 58,4 \\
\hline \multirow{3}{*}{$\begin{array}{l}\text { Sikap } \\
\bullet \\
\bullet\end{array}$} & & 31,01 & & & 37,96 & & \\
\hline & $\begin{array}{l}\text { Negatif } \\
\text { Positif }\end{array}$ & & & 65 & & 25 & 41,6 \\
\hline & & & $\begin{array}{l}39 \\
21\end{array}$ & 35 & & 35 & 58,4 \\
\hline
\end{tabular}

Berdasarkan 1 di atas dapat dijelaskan bahwa sebelum dilakukan penyuluhan tentang KDRT, jumlah responden yang memiliki pengetahuan baik yaitu $22(36,7 \%)$, sedangkan jumlah responden yang pengetahuannya kurang yaitu 38 (63,3\%). Sebagian besar responden memiliki pengetahuan yang kurang sebelum diberikan penyuluhan karena pengetahuan seluruh istri masih kurang tentang KDRT. Selanjutnya berdasarkan tabel 5.1.1 di atas dapat dijelaskan bahwa sebelum dilakukan penyuluhan tentang KDRT, jumlah responden yang memiliki sikap positif yaitu 21 (35\%), sedangkan jumlah responden yang memiliki sikap negatif yaitu 39 (65\%). Sebagian besar responden memiliki sikap yang kurang sebelum diberikan penyuluhan karena seluruh istri masih membudidayakan kedudukan perempuan lenih rendah dibandingkan laki-laki, sehingga seluruh istri cenderung diam saja ketika menerima tindakan KDRT. Lalu berdasarkan tabel 5.1.1 di atas dapat dijelaskan bahwa sesudah dilakukan penyuluhan tentang KDRT, jumlah responden yang memiliki pengetahuan baik yaitu 35 (58,4\%), sedangkan jumlah responden yang memiliki pengetahuan kurang yaitu 25 (41,6\%). Pengetahuan responden menjadi lebih baik karena adanya intervensi berupa penyuluhan yang memberikan informasi tentang KDRT sehingga responden lebih memahami tentang KDRT. Selanjutnya, berdasarkan tabel 5.1.1 di atas dapat dijelaskan bahwa sesudah dilakukan penyuluhan tentang KDRT, jumlah responden yang memiliki sikap positif yaitu 35 (58,4\%), sedangkan jumlah responden yang memiliki sikap negatif yaitu 25 (41,6\%). Sebagian besar responden memiliki sikap yang positif sesudah diberikan penyuluhan karena responden menjadi memahami apa yang seharusnya dilakukan ketika terjadi KDRT. 
Tabel 2

Efektivitas Penyuluhan Dengan Media Poster Terhadap Pengetahuan Dan Sikap Istri Pada Kekerasan Dalam Rumah Tangga

\begin{tabular}{|c|c|c|c|c|c|c|c|}
\hline \multirow[b]{2}{*}{ Variabel } & \multicolumn{3}{|c|}{ Pre - Test } & \multicolumn{3}{|c|}{ Post - Test } & \multirow[t]{2}{*}{ P-Value } \\
\hline & Mean & $\mathbf{n}$ & $\%$ & Mean & $\mathbf{n}$ & $\%$ & \\
\hline $\begin{array}{l}\text { Pengetahuan } \\
\text { - } \quad \text { Kurang } \\
\text { - } \quad \text { Baik }\end{array}$ & & $\begin{array}{l}38 \\
22\end{array}$ & $\begin{array}{l}63,3 \\
36,7\end{array}$ & & $\begin{array}{l}25 \\
35\end{array}$ & $\begin{array}{l}41,6 \\
58,4\end{array}$ & 0,002 \\
\hline $\begin{array}{l}\text { Sikap } \\
\text { - } \quad \text { Negatif } \\
\text { - } \quad \text { Positif }\end{array}$ & 31,01 & $\begin{array}{l}39 \\
21\end{array}$ & $\begin{array}{l}65 \\
35\end{array}$ & 37,96 & $\begin{array}{l}25 \\
35\end{array}$ & $\begin{array}{l}41,6 \\
58,4\end{array}$ & 0,009 \\
\hline
\end{tabular}

Berdasarkan tabel 2 di atas, diketahui bahwa hasil analisis pada variabel pengetahuan yaitu menunjukkan bahwa jumlah pengetahuan yang kurang sebelum dilakukan intervensi sebanyak 38 (63,3\%), dan menjadi lebih baik setelah dilakukan intervensi sebanyak $25(41,6 \%)$, sedangkan pengetahuan yang baik sebelum dilakukan intervensi yakni $22(36,7 \%)$ menjadi lebih baik setelah dilakukan intervensi sebanyak 34 (58,4\%), dengan $P$ Value $0.002<0.05$ yang artinya ada efektivitas antara pengetahuan sebelum dan sesudah dilakukan intervensi. Pengetahuan responden menjadi lebih baik karena adanya intervensi berupa penyuluhan yang memberikan informasi tentang KDRT sehingga responden lebih memahami tentang KDRT.

Selanjutnya berdasarkan tabel 1 di atas, diketahui bahwa hasil analisis pada variabel sikap yaitu menunjukkan bahwa jumlah sikap yang negatif sebelum dilakukan intervensi sebanyak 39 (65\%), dan menjadi berkurang setelah dilakukan intervensi sebanyak $25(41,6 \%)$, sedangkan sikap yang positif sebelum dilakukan intervensi yakni 21 (35\%) menjadi lebih baik setelah dilakukan intervensi sebanyak 35 (58,4\%), dengan nilai $P$-Value $0.009<0.05$ yang artinya ada efektivitas antara sikap sebelum dan sesudah dilakukan intervensi. Sebagian besar responden memiliki sikap yang positif sesudah diberikan penyuluhan karena responden menjadi memahami apa yang seharusnya dilakukan ketika terjadi KDRT.

\section{Pengetahuan Istri pada KDRT di Jalan Masjid Baru RT 12 RW 01 Jakarta Selatan}

Setelah dilakukan pengolahan data pada penelitian mengenai pengetahuan dan sikap istri sebelum dan sesudah diberikan penyuluhan tentang KDRT di Jalan Masjid Baru RT 12 RW 01 Jakarta Selatan pada periode Juni sampai dengan Juli tahun 2018, penulis membahas variabel yang diteliti yang mengacu pada teori dalam tinjauan pustaka dan hasil yang diperoleh dalam penelitian. Hasil penelitian menunjukkan terjadi peningkatan pengetahuan dan sikap pada responden antara sebelum dan sesudah diberikan penyuluhan tentang KDRT. Sebelum diberikan penyuluhan, pengetahuan responden kurang tentang KDRT karena responden kurang mendapatkan informasi tentang definisi, jenis-jenis, faktor-faktor, serta undang-undang yang mengatur KDRT. Kemudian peneliti memberikan intervensi berupa penyuluhan yang memberikan informasi tentang KDRT sehingga menambah pengetahuan responden tentang KDRT.

Hal ini sesuai dengan teori yang dikemukakan oleh Notoatmodjo bahwa pengetahuan adalah hasil dari "tahu", dan ini terjadi setelah seseorang melakukan penginderaan melalui panca indera penglihatan, pendengaran, 
penciuman, dan rasa tahu. Sebagian pengetahuan manusia diperoleh melalui mata dan telinga. Pengetahuan atau kognitif adalah merupakan domain yang sangat penting untuk terbentuknya tindakan seseorang. Di samping itu seseorang dapat juga memperoleh pengetahuan diri dari orang lain melalui pendengaran atau informasi, melihat dan meraba, baik secara langsung maupun tidak langsung melalui alat-alat media cetak maupun media elektronik. Pengetahuan dipengaruhi oleh beberapa faktor yaitu usia, pendidikan, pekerjaan, pengalaman, kebudayaan, dan informasi.

Hal ini sesuai dengan penelitian yang telah dilakukan oleh Retno Kusuma Wati pada tahun 2014 dengan judul "Efektivitas Penyuluhan Kesehatan Reproduksi terhadap Pengetahuan dan Sikap Seks Bebas pada Siswa Kelas X di SMAN 2 Banguntapan tahun 2014" bahwa didapatkan hasil pengetahuan siswa tentang kesehatan reproduksi remaja sebelum diberikan penyuluhan pada kelompok eksperimen dan kontrol. Pre-test kelompok kontrol cukup dengan jumlah 41 siswa $(68,3 \%)$, setelah diberikan penyuluhan meningkat menjadi baik dengan jumlah 30 siswa (50,0\%), dan pada pre-test kelompok kontrol cukup dengan jumlah 45 siswa (76,3\%), pada post-test dengan kategori cukup berjumlah 47 siswa (79,7\%).

Asumsi peneliti tentang pengetahuan terhadap KDRT sudah baik tetapi masih ada sebagian yang kurang, dapat dilihat dari hasil penelitian yang telah dilakukan, yaitu masih ada responden yang mempunyai pengetahuan kurang. Dalam hal ini dapat diketahui bahwa pengetahuan seseorang berbeda-beda karena dipengaruhi oleh beberapa faktor yaitu usia, pendidikan, pekerjaan, pengalaman, kebudayaan, dan informasi. Faktor yang lebih dominan adalah pendidikan. Pendidikan responden cenderung kurang, sehingga beberapa responden sulit untuk menerima pengetahuan yang didapat, kemudian karena masih rendahnya pendidikan responden, responden cenderung tidak dapat mengembangkan diri.

\section{Sikap Istri pada KDRT di Jalan Masjid Baru RT 12 RW 01 Jakarta Selatan}

Hasil penelitian menunjukkan terjadi peningkatan sikap pada responden antara sebelum dan sesudah diberikan penyuluhan mengenai KDRT. Sebelum dilakukan penyuluhan, responden masih membudidayakan kedudukan perempuan lebih rendah dibandingkan laki-laki, sehingga responden cenderung takut dan diam saja ketika mengalami KDRT. Kurangnya informasi mengenai proses pelaporan kasus KDRT juga menjadi sebab responden tidak dapat melaporkan tindakan KDRT. Kemudian peneliti memberikan penyuluhan dengan media poster yang berisi ajakan kepada responden agar tidak diam saja apabila mengalami KDRT. Poster tersebut dapat membentuk sikap responden menjadi positif. Selanjutnya peneliti menjelaskan proses pelaporan kasus KDRT yaitu pertama melalui jalur hukum Unit Pelayanan Perempuan dan Anak (UPPA) di Polres terdekat. Selain itu korban atau keluarga juga dapat meminta bantuan dari relawan pendamping untuk mendampingi korban melaporkan ke pihak kepolisian. Setelah itu korban akan mengalami pemulihan psikologis yang didampingi oleh lembaga yang berbasis psikologis hingga pulih.

Sesuai dengan teori mengenai terbentuknya sikap yang dikemukakan oleh Dr.Saifuddin Azwar bahwa sikap dapat terbentuk dan dipengaruhi oleh media massa sebagai sarana komunikasi, berbagai bentuk media massa seperti televisi, radio, surat kabar,poster, majalah, buku, dan lain-lain, mempunyai pengaruh besar dalam sikap melalui pembentukan opini dan kepercayaan seseorang. Dalam penyampaian informasi sebagai tugas pokoknya, media massa membawa pula pesan-pesan yang berisi sugesti yang dapat mengarahkan opini seseorang. Adanya 
informasi baru mengenai sesuatu hal memberikan landasan kognitif baru bagi terbentuknya sikap terhadap hal tersebut.

Pesan-pesan sugestif yang dibawa oleh informasi tersebut, apabila cukup kuat, akan memberi dasar afektif dalam menilai sesuatu hal sehingga terbentuklah arah sikap tertentu ${ }^{20}$. Hal ini sesuai dengan penelitian yang telah dilakukan oleh Retno Kusuma Wati pada tahun 2014 dengan judul "Efektivitas Penyuluhan Kesehatan Reproduksi terhadap Pengetahuan dan Sikap Seks Bebas pada Siswa Kelas X di SMAN 2 Banguntapan tahun 2014" bahwa didapatkan hasil sikap siswa tentang kesehatan reproduksi remaja sebelum dan sesudah penyuluhan pada kelompok eksperimen dan kontrol. Hasil pre-test kelompok eksperimen cukup dengan jumlah 43 siswa (71,7\%), setelah diberikan penyuluhan meningkat menjadi baik sebanyak 36 siswa (60,0\%), sedangkan hasil pre-test pada kelompok kontrol kategori cukup berjumlah 39 siswa $(66,1 \%)$ dan hasil post-test pada kategori cukup meningkat menjadi 41 siswa $(69,5 \%)$.

Asumsi peneliti tentang sikap terhadap KDRT sudah baik tetapi masih ada sebagian yang kurang, dapat dilihat dari hasil penelitian yang telah dilakukan, yaitu masih ada sebagian responden yang memiliki sikap kurang terhadap KDRT. Dalam hal ini tidak dapat dipungkiri bahwa sikap seseorang dipengaruhi oleh beberapa faktor, yaitu pengalaman pribadi, pengaruh orang lain yang dianggap penting, kebudayaan, media massa, lembaga pendidikan dan agama, serta faktor emosional. ${ }^{20}$ Faktor yang lebih dominan terjadi pada responden yang menjadi sebab masih memiliki sikap negatif setelah dilakukan intervensi adalah kebudayaan. Tidak mudah merubah budaya yang sudah lama diterapkan pada kehidupan seseorang. Budaya yang terjadi bahwa kedudukan perempuan lebih rendah dibandingkan laki-laki, sehingga responden takut dan diam saja ketika mengalami KDRT.

\section{KESIMPULAN DAN REKOMENDASI}

Berdasarkan hasil penelitian dan pembahasan yang sudah diuraiakan pada BAB sebelumnya maka dapat diambil kesimpulan sebagai berikut: Adanya efektivitas penyuluhan dengan media poster terhadap KDRT pada istri sebelum dan sesudah diberikan penyuluhan di Jalan Masjid Baru RT 12 RW 01, Jakarta Selatan Tahun 2018, Adanya efektivitas pengetahuan istri sebelum dan sesudah diberikan penyuluhan pada KDRT di Jalan Masjid Baru RT 12 RW 01, Jakarta Selatan Tahun 2018, Adanya efektivitas sikap istri sebelum dan sesudah diberikan penyuluhan pada KDRT di Jalan Masjid Baru RT 12 RW 01, Jakarta Selatan Tahun 2018. Rekomendasi Bagi Tempat Penelitian : Diharapkan pengetahuan dan sikap seluruh istri menjadi lebih baik pada tindakan KDRT agar tidak semakin meningkat jumlah korban karena kasus KDRT. Selain itu diharapkan kepada tokoh masyarakat agar berperan aktif dalam pemberian informasi tentang KDRT, dan mendampingi korban apabila terjadi kasus KDRT. Bagi Institusi Pendidikan STIKes Mitra RIA Husada : Diharapkan hasil penelitian ini dapat bermanfaat sebagai referensi dan dapat memberikan masukan kepada institusi pendidikan untuk memberikan penyuluhan tentang KDRT di lokasi dan pada sasaran yang tepat. Bagi Peneliti Selanjutnya : Diharapkan bagi peneliti selanjutnya yang tertarik dengan tema yang sama dapat melakukan penelitian yang lebih kreatif dengan jenis media penyuluhan lainnya sehingga penelitian lebih bervariasi dan lebih baik lagi. 


\section{REFERENSI}

1. Fransisca. Kekerasan Dalam Rumah Tangga. 2015;

2. Djaruu SAF, Kanine tinneke T. Application of the Stress Adaptation Concept By Roy Calista on. 2016;3(1):88-97.

3. Epriliawati M, Setiati S, Rumende C. Universitas indonesia. Depok; 2014. 83 p.

4. Ayu P, Pradnya M, Wedaningtyas P, Herdiyanto YK. Memahami Resilensi Pada Perempuan Yang Mengalami KDRT Dan Tinggal Di Pedesaan. 2017;4(1):9-19.

5. Komnas Perempuan. Lembar Fakta Catatan Tahunan (CATAHU) Komnas Perempuan Tahun 2017 [Internet]. 2017. [cited 2018 Jan 1]. Available from: https://www.komnasperempuan.go.id/file/pdf_file/2017 Siaran Pers/Lembar Fakta Catahu 2017.pdf

6. Guse Prayudi, SSH. M. Berbagai Aspek Tindak Pidana Kekerasan Dalam Rumah Tangga. Yogyakarta: Merkid Press; 2015.

7. Moerti Hadiati. Kekerasan Dalam Rumah Tangga: Dalam Perspektif Yuridis-Viktimologis. Jakarta: Sinar Grafika; 2016.

8. Erich Fromm. Akar Kekerasan. Jakarta: Pustaka Pelajar; 2016.

9. Ismu Gunadi. Hukum Pidana. Jakarta: Ganesha; 2015.

10. Irianto K. Kesehatan Reproduksi (Reproductive Health) Teori dan Praktikum. Bandung: Alfabeta; 2015.

11. Agus Hiplunudin. Politik Gender. Jakarta: Calpulis; 2017.

12. Erich Fromm. Pengantar Umum Psikoanalisis A Gender Introduction To Psychoanalysis. Jakarta: Pustaka Pelajar; 2017.

13. R. Wiyono. Pengadilan Hak Asasi Manusia. Jakarta: Ganesha; 2016.

14. Andrew R, Simanjuntak O. Hubungan Pendamping Dengan Korban KDRT Dalam Usaha Pemberdayaan Perempuan. 2016;(4).

15. S. Fitrianingsih. Faktor-Faktor Penyebab Tindakan Kekerasan Pada Perempuan Dalam Rumah Tangga. 2016;

16. Lisa S. Alasan Istri Sebagai Korban KDRT. 2015;VII:20-43.

17. Suharyat Y. Hubungan Antara Sikap, Minat dan Perilaku Manusia. Region. 2009;I(3):1-19.

18. KBBI. Pengetahuan [Internet]. [cited 2018 Feb 15]. Available from: https://kbbi.web.id/pengetahuan

19. A. Wawan. Teori dan Pengukuran Pengetahuan, Sikap, dan Perilaku Manusia. Jakarta: Medical Book; 2016.

20. Dr. Saifuddin Azwar M. Sikap Manusia. Yogyakarta: Pustaka Pelajar; 2016.

21. Soekidjo Notoatmodjo. Promosi Kesehatan dan Ilmu Perilaku. Jakarta: Rineka Cipta; 2010.

22. Novita Ika Wardani. Buku Ajar Promosi Kesehatan. Jakarta: Cv. Trans Info Media; 2016.

23. Retno Kusuma Wati. Efektivitas Penyuluhan Kesehatan Reproduksi Terhadap Pengetahuan Dan Sikap Seks Bebas Pada Siswa Kelas X Di SMAN 2 Banguntapan Tahun 2014. 2014;

24. Prof. Dr. Sugiyono. Metode Penelitian. Jakarta: Ganesha; 2016.

25. Dr. Ir. Harinaldi. Prinsip-Prinsip Statistik. Jakarta: Erlangga; 2015.

26. Dr. Edi Riadi. Statitiska Penelitian. Yogyakarta: ANDI Yogyakarta; 2016. 